\title{
Treating rare diseases with the cinema: Can popular movies enhance public understanding of rare diseases?
}

\author{
Jan Domaradzki* (i)
}

\begin{abstract}
Background: Rare diseases (RDs) constitute an important public health issue. However, although public awareness campaigns focus on the improvement of undergraduate and postgraduate education, also popular culture may serve as an educational tool in this field. This study aims to analyse how rare genetic diseases are depicted in popular movies.

Methods: Twenty popular movies on RDs were analysed quantitatively. The main categories included in the coding frame were: disease, patient, physician/scientist and psychosocial issuses related to RDs.

Results: The majority of movies do not contain adequate scientific information on RDs. Consequently, their cinematic image is either inaccurate or simplified. However, the cinema does take up some important topics in the field of RDs and highlight their ethical, psychosocial, legal or economic dimension: the diagnostic and therapeutic odyssey, the role of RD patients' advocacy groups in the production of scientific knowledge, the problem of orphan drugs, the stigmatisation of and discrimination against RD patients, and the impact of diagnosis on one's concept of self and parents' feelings of guilt.

Conclusion: Although popular movies mostly focus on RD patients' problems of daily living and rarely describe clinical aspects of RDs, they do have an educational potential. Thus, movies can help to raise the public's awareness on the psychospocial and economic problems faced by RD patients and their families.
\end{abstract}

Keywords: Rare genetic diseases, Cinema, Popular movies, Science and movies, Science education

\section{Introduction}

Rare diseases (RDs) are chronically debilitating or lifethreatening conditions with a high level of complexity despite their low prevalence of less than 5 per 10,000 persons [1]. Although they do seem rare, it is estimated that $6-8 \%$ of the world's population, i.e. approximately 300-350 million people, are affected by RDs. This means that one out of every 15 persons worldwide could be affected, or that if all of the people suffering

*Correspondence: jandomar@ump.edu.pl

Department of Social Sciences and Humanities, Poznan University

of Medical Sciences, Rokietnicka 7, St., 60-806 Poznan, Poland from RDs lived in one country, it would be the world's third most populous country. While there are between 6,000 and 8,000 RDs, $80 \%$ are caused by genetic mutations and $50 \%$ of RDs patients are children. Simultaneously, although in recent decades there has been progress in the research, development and marketing of orphan drugs, due to their genetic origin no cure exists for the vast majority of RDs. Indeed, even though during the last four decades the number of orphan drugs designations granted have more than quadrupled, still it is estimated that only $5 \%$ of RDs have approved drug treatment. Moreover, $75 \%$ of orphan products approved treat only one RD and have no other use [2,3]. What is equally problematic is that approximately $50 \%$ of RDs original author(s) and the source, provide a link to the Creative Commons licence, and indicate if changes were made. The images or other third party material in this article are included in the article's Creative Commons licence, unless indicated otherwise in a credit line to the material. If material is not included in the article's Creative Commons licence and your intended use is not permitted by statutory regulation or exceeds the permitted use, you will need to obtain permission directly from the copyright holder. To view a copy of this licence, visit http://creativecommons.org/licenses/by/4.0/. The Creative Commons Public Domain Dedication waiver (http://creativeco mmons.org/publicdomain/zero/1.0/) applies to the data made available in this article, unless otherwise stated in a credit line to the data. 
do not have a disease specific foundation supporting or researching their condition $[4,5]$. Another problem is that RDs are often overlooked by medical education [6-11], government officials and policy makers, public health programs and news media $[12,13]$. Indeed, RD patients and their caregivers often complain over the lack of knowledge about RDs from healthcare professionals and feel frustrated with their negative experience with health and social care services and express a general lack of trust in the standard of healthcare [14-16].

Thus, it has been argued that because RDs constitute an important medical and social challenge and an urgent public health issue, they should be prioritized by policymakers, healthcare providers and medical education campaigns alike [17-20]. Although in recent years a lot has been done to enhance RD policies, through orphan drug reimbursement systems and government actions [21-23], there are still many gaps in the public awareness on RDs. Consequently, calls for initiatives to improve both healthcare professionals' knowledge and the public's awareness on RDs have emerged [6-11]. Simultaneously, while many focus on the improvement of undergraduate and postgraduate education, it has been suggested that also popular culture, and movies in particular, may serve as an educational tool in this field [24-27]. The reason for this is put forward that while only a small portion of the general public have ever met a patient suffering from an $\mathrm{RD}$, the majority derive their impressions on RDs from other sources, primarily the entertainment media and popular culture. And because during the last decades, parallel to the dynamic progress in genetic knowledge and the development of novel orphan drugs, many movies on RDs have been released, the cinema may familiarize the public with diseases that are typically foreign to the everyday medical practice and help facilitate the transfer of knowledge and attitudes on RDs to medical students, healthcare professionals and the public.

Thus, this study analyses how rare genetic diseases are presented in popular movies. At the same time, while it was primarily focused on the dominant images of RDs in films, I was also interested in the following questions:

- How do films depict RDs? Do they familiarize the audience with the knowledge on the symptoms, etiology and treatment of RDs?

- How do films frame RD patients?

- What images of physicians and scientists emerge from popular movies?

- What are the psychosocial, ethical and economic implications of RDs depicted in movies?

\section{Material and methods}

The sample of movies was designed according to a content-based criteria. A movie search was conducted in May 2021 using the two electronic online movie databases: Filmweb (http://www.filmweb.pl) and Internet Movie Database (http://www.imdb.com). Then the available plot descriptions were compared with predefined key words: "rare disease", "genetic disease", "orphan disease", "terminal illness". Additionally, data from the movie databases included the year of production, genre, producing country and director.

To provide more homogenous results, television series with a medical theme, i.e. ER, The Good Doctor, Code Black, Grey's Anatomy, Private Practice or The Resident were excluded. Although these movies could add something into the discussion about the cinematic image of RDs, as some episodes featured patients with such diseases, this research was limited only to feature films where RDs were the main theme. Documentary movies [28] on RDs, such as: My Flesh and Blood, Our curse, Life according to Sam, Rare or Esto no es una persona were also omitted. While especially this type of movies would add some diversity to the genres, they have been disregarded because what I was rather interested in was how popular movies framed orphan diseases. Movies picturing RDs that are not of genetic origin, such as Brain on Fire (anti-NMDA receptor encephalitis) or Awakenings (Encephalitis lethargica) were also excluded. Similarly, films where the RD is a backstory and was only mentioned but was not developed, i.e., The Big Sick (adultonset Still's disease), Shallow Hal (spina bifida), Glass (osteogenesis imperfecta), The 6th Day (cystic fibrosis), Dancer in the Dark (Pigmentary retinitis), The Sea Inside/Mar adentro (cadasil), Amélie/Le Fabuleux destin d'Amélie Poulain (osteogenesis imperfecta) or Unbreakable (osteogenesis imperfecta), were also omitted. Also movies addressing fictional RDs, i.e. Star Trek Nemesis ("Shalaft's Syndrome"), Blade Runner ("Methuselah Syndrome"), The Curious Case of Benjamin Button ("Button disease") or Waterless (undefined allergy to water) were not taken into consideration. Strictly for this reason, although the main character in the movie Poder has albinism, it was excluded because he has also paranormal powers, including telepathy. Finally, movies in which parents make their children believe they suffer from an RD (i.e. severe combined immunodeficiency) due to their overprotective nature, were also excluded (Bubble Boy and Everything, Everything).

Simultaneously, I am aware that while the selection of the movies included in the analysis neither is nor could be representative, it does not exhaust other interpretations. However, I believe that the selected movies possess a narrative utility because they provide a unique insight 


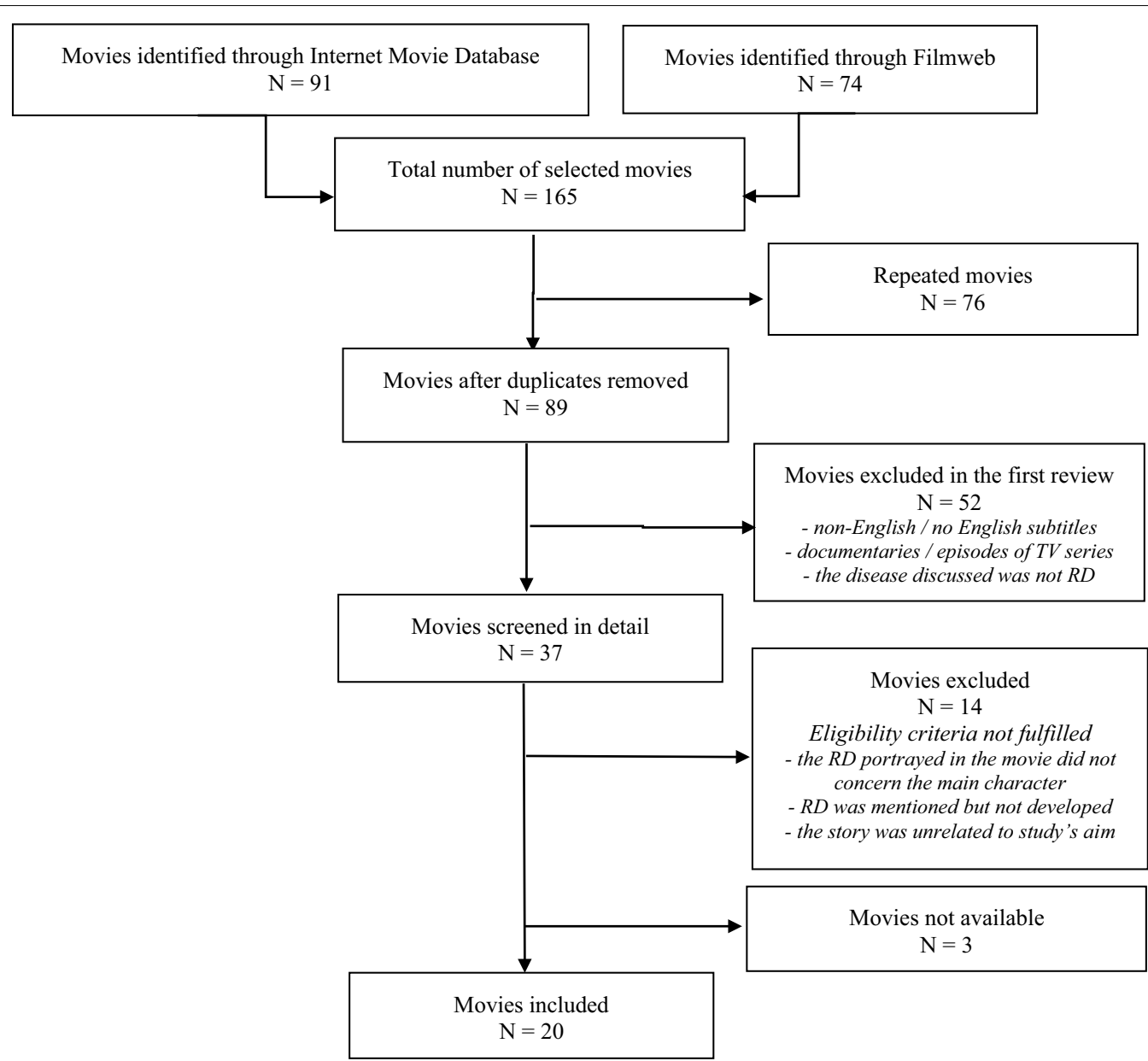

Fig. 1 Review and selection process of movies included

into the cultural images of RDs in movies that can easily be recognized by the public. I am also convinced that this research shows that movies both reflect and (re)construct the social images of rare genetic disease. Additionally, to make sure that the selected movies reached a wider audience, their box office have been checked (http://www. boxofficemojo.com), which, at least to some degree, reflects the scale of their reception.

The initial search identified 165 movies, which were first assessed based on their titles and plot summaries (Fig. 1).

After removing duplicates, 89 films were evaluated in more detail. The first stage of the screening excluded 52 movies that were non-English movies or had no English subtitles, were documentaries or episodes of television series, or because the disease discussed in the movie was not relevant to the key issue of rare genetic diseases. From the remaining 37 movies, fourteen were excluded because they did not meet the eligibility criteria, i.e. the RD portrayed in the movie did not concern the main character, was only mentioned but not developed or because the story was incongruous to this study's aim. Additionally, three movies were not available. Thus, of all the movies that met the inclusion criteria, 20 were included, watched and analysed quantitativly (Table 1).

A content analysis started with familiarization with the data, which involved watching all the movies. After becoming immersed with their content, a standardized and structured data extraction tool was developed to include the most important features present in the films. The main categories included in the coding frame were:

- rare disease: this category refers to the way rare genetic disease is depicted in films and includes: the type of RD, description of its symptoms, etiology, therapy, suffering, type of care, death and dying;

- RD patient and the family: this category embodies patients' demographic characteristics, including, sex, age and ethnicity, prognosis, place and type of 
Table 1 List of selected movies $(N=20)$

\begin{tabular}{|c|c|c|c|c|c|c|}
\hline Movie tittle & Type of disease & Year & Genre & Country & Director & Box office \\
\hline $\begin{array}{l}\text { The Boy in the Plastic Bubble (TV } \\
\text { movie) }\end{array}$ & $\begin{array}{l}\text { Severe combined immunode- } \\
\text { ficiency }\end{array}$ & 1976 & Biography, Drama & USA & Randal Kleiser & No data available \\
\hline The Elephant Man & Proteus syndrome $\mathrm{a}^{\mathrm{a}}$ & 1980 & Biography, Drama & USA & David Lynch & $\$ 26,023,706$ \\
\hline Mask & Craniodiaphyseal dysplasia & 1985 & Biography, Drama & USA & Peter Bogdanovich & $\$ 48,230,162$ \\
\hline $\begin{array}{l}\text { Crystal Heart (Corazón de } \\
\text { cristal) (TV movie) }\end{array}$ & $\begin{array}{l}\text { Severe combined immunode- } \\
\text { ficiency }\end{array}$ & 1986 & Drama, Romance & Spain/USA & Gil Bettman & No data available \\
\hline $\begin{array}{l}\text { Alex: The Life of a Child (TV } \\
\text { movie) }\end{array}$ & Cystic fibrosis & 1986 & Biography, Drama & USA/Canada & Robert Markowitz & No data available \\
\hline Lorenzo's Oil & Adrenoleukodystrophy & 1992 & Biography, Drama & USA & George Miller & $\$ 7,286,388$ \\
\hline Children of the Dark (TV movie) & Xeroderma pigmentosum & 1994 & Drama & USA & Michael Switzer & No data available \\
\hline Jack & Werner syndrome & 1996 & Comedy, Drama & USA & Francis Ford Coppola & $\$ 58,620,973$ \\
\hline Sixth Happiness & Osteogenesis imperfecta & 1997 & Drama & UK & Waris Hussein & No data available \\
\hline The Mighty & Morquio syndrome & 1998 & Comedy, Drama & USA & Peter Chelsom & $\$ 2,652,246$ \\
\hline Simon Birch & Osteogenesis imperfecta & 1998 & Comedy, Drama & USA & Mark Steven Johnson & $\$ 18,253,415$ \\
\hline Jack and Jill vs. the World & Cystic fibrosis & 2008 & Drama, Romance & USA/Canada & Vanessa Parise & No data available \\
\hline Paa (Father) & Progeria & 2009 & Comedy, Drama & India & R. Balki & $\$ 9,696,629$ \\
\hline Extraordinary Measures & Pompe disease & 2010 & Drama & USA & Tom Vaughan & $\$ 15,134,293$ \\
\hline $\begin{array}{l}\text { And I'll Be Dead Tomorrow Noon } \\
\text { (Und morgen mittag bin ich tot) }\end{array}$ & Cystic fibrosis & 2013 & Drama & $\begin{array}{l}\text { Germany/ } \\
\text { Netherlands/ } \\
\text { Belgium }\end{array}$ & Sacha Polak & No data available \\
\hline Wonder & Treacher Collins syndrome & 2017 & Drama, Family & USA/Hong Kong & Stephen Chbosky & $\$ 306,209,289$ \\
\hline Midnight Sun & Xeroderma pigmentosum & 2018 & Drama, Romance & USA & Scott Speer & $\$ 27,365,467$ \\
\hline Five Feet Apart & Cystic fibrosis & 2019 & Drama, Romance & USA & Justin Baldoni & $\$ 91,527,795$ \\
\hline Ondine & $\begin{array}{l}\text { Congenital central hypoventi- } \\
\text { lation syndrome }\end{array}$ & 2019 & Drama & Poland & Tomasz Śliwiński & No data available \\
\hline $\begin{array}{l}\text { More Beautiful for Having Been } \\
\text { Broken }\end{array}$ & Fanconi anaemia & 2019 & Drama & USA & Nicole Conn & No data available \\
\hline
\end{tabular}

${ }^{a}$ Although for many years it has been argued that Joseph Merrick, the cinematic 'elephant man', was afflicted with Neurofibromatosis type I, most recent studies have demonstrated that he actually suffered from Proteus syndrome [29]

death, patient's self-image and emotional reactions, patient's problems and needs, family reaction;

- physician and/or scientist: this category refers to physician's demographic characteristics, including, sex, age, ethnicity, specialization, position, type of research, place of work, interest in patient's disease including physician-patient communication;

- psychosocial issues related to RDs which included stigmatization, isolation/social exclusion, discrimination and reduced life opportunities.

These four categories were selected because they describe and identify the key points in the scientific literature [30-33]. Moreover, I believe they represent the public understanding of RDs in movies.

In the last stage of analysis, all the movies were viewed carefully a second time and every scene or passage that supported pre-determined categories mentioned above was noted on the coding sheet. To achieve this I have taken into account both verbal and nonverbal messages. After comparing all notes from each movie, the repetitive patterns were found and analyzed.

\section{Results}

Rare diseases' symptoms, etiology and treatment

While the cinema covers a wide variety or RDs, it was cystic fibrosis $(n=20 \%)$, severe combined immunodeficiency, osteogenesis imperfecta and xeroderma pigmentosum $(\mathrm{n}=10 \%$ apiece) that were the most prevalent in the movies (Table 2). Simultaneously, although most of the movies introduced the disease either by mentioning its name $(75 \%)$, describing the etiology of the disease $(50 \%)$ or by highlighting its most common symptoms (75\%), still many others give only a very brief description of the disease or provide no such information whatsoever. Thus, although films present a variety of symptoms, ranging from immunodeficiency, abnormal growth, loss of weight, breathing difficulties, problems with movement, pain and mental 
Table 2 Characteristics of rare diseases in the movies $(N=20)$

\begin{tabular}{|c|c|c|}
\hline & $\mathbf{N}$ & (\%) \\
\hline \multicolumn{3}{|l|}{ Type of disease } \\
\hline Severe combined immunodeficiency & 2 & 10 \\
\hline Craniodiaphyseal dysplasia & 1 & 5 \\
\hline Proteus syndrome & 1 & 5 \\
\hline Adrenoleukodystrophy & 1 & 5 \\
\hline Xeroderma pigmentosum & 2 & 10 \\
\hline Werner syndrome & 1 & 5 \\
\hline Osteogenesis imperfecta & 2 & 10 \\
\hline Morquio syndrome & 1 & 5 \\
\hline Cystic fibrosis & 4 & 20 \\
\hline Progeria & 1 & 5 \\
\hline Pompe disease & 1 & 5 \\
\hline Treacher Collins syndrome & 1 & 5 \\
\hline Fanconianaemia & 1 & 5 \\
\hline Congenital central hypoventilation syndrome & 1 & 5 \\
\hline \multicolumn{3}{|l|}{ Mentions/describes the disease } \\
\hline Yes & 15 & 75 \\
\hline No & 5 & 25 \\
\hline \multicolumn{3}{|l|}{ Describing etiology of disease } \\
\hline Yes & 10 & 50 \\
\hline No & 10 & 50 \\
\hline \multicolumn{3}{|l|}{ Describing/explaining symptoms } \\
\hline Yes & 15 & 75 \\
\hline No & 5 & 25 \\
\hline \multicolumn{3}{|l|}{ Symptoms occurring in movies* } \\
\hline Immunodeficiency & 3 & 15 \\
\hline Abnormal growth & 7 & 35 \\
\hline Problems with movement & 8 & 40 \\
\hline Breathing difficulties & 7 & 35 \\
\hline Premature aging & 2 & 10 \\
\hline Muscle weakness & 4 & 20 \\
\hline Bone fractures & 2 & 10 \\
\hline Skin problems, i.e. blisters & 3 & 15 \\
\hline Seizures, convulsions & 2 & 10 \\
\hline Metabolic/gastrointestinal problems & 3 & 15 \\
\hline Neurological problems & 2 & 10 \\
\hline Heart problems & 4 & 20 \\
\hline Mental retardation & 2 & 10 \\
\hline Pain & 7 & 35 \\
\hline Caught & 6 & 30 \\
\hline Copious phlegm & 4 & 20 \\
\hline Blood spitting & 1 & 5 \\
\hline Fatigue/tiredness & 2 & 10 \\
\hline Loss of weight/inability to gain weight & 6 & 30 \\
\hline Loss of hair & 1 & 5 \\
\hline Loss of appetite & 1 & 5 \\
\hline Loss of concentration & 1 & 5 \\
\hline Loss of consciousness & 2 & 10 \\
\hline Loss of speech & 1 & 5 \\
\hline
\end{tabular}

Table 2 (continued)

\begin{tabular}{|c|c|c|}
\hline & $\mathbf{N}$ & (\%) \\
\hline Mood swings & 1 & 5 \\
\hline Depression & 1 & 5 \\
\hline \multicolumn{3}{|l|}{ Therapy } \\
\hline Medications & 6 & 30 \\
\hline Operation & 3 & 15 \\
\hline Inhalations & 4 & 20 \\
\hline Enzyme therapy & 1 & 5 \\
\hline Unspecified experimental therapy & 4 & 20 \\
\hline Does not mention & 4 & 20 \\
\hline No therapy & 15 & 20 \\
\hline \multicolumn{3}{|l|}{ Medications } \\
\hline Yes & 6 & 30 \\
\hline No & 14 & 70 \\
\hline \multicolumn{3}{|l|}{ Suffering } \\
\hline Yes & 9 & 45 \\
\hline No & 11 & 55 \\
\hline \multicolumn{3}{|l|}{ Hospital/palliative care } \\
\hline Yes & 7 & 35 \\
\hline No & 13 & 65 \\
\hline \multicolumn{3}{|l|}{ Death } \\
\hline Yes & 10 & 50 \\
\hline No & 10 & 50 \\
\hline \multicolumn{3}{|l|}{ Patient Advocacy Group } \\
\hline Yes & 2 & 10 \\
\hline No & 18 & 90 \\
\hline
\end{tabular}

*Many symptoms appeared in more than one movie

retardation, and highlight the complexity and severity of RDs, frequently, they lack a more detailed description. Thus, the RD's explanation is often reduced to a couple of sentences expressed in pseudoscientific jargon and rests on simplifications. For example, while very few movies explain the molecular mechanism of the given disease, many others contain very little scientific information on the RD discussed in the movies. Consequently, because the image of some RDs depicted in movies is often inaccurate or simplified, the educational nature of movies on the clinical dimension of RDs is very limited.

Addtionally, although many movies depicted some kind of treatment, including medications (30\%), operations $(15 \%)$ or some experimental therapy (20\%), the majority either do not mention these (20\%) or stress explicitly that there is no evaluable treatment for RDs (20\%). $70 \%$ of the cinematic patients did not receive any type of medciations, $45 \%$ suffered pain and $35 \%$ received hospital or palliative care. In $50 \%$ of the movies the disease leads to the patient's death. Interestingly, only two movies made any reference to a patient advocacy group (35\%). 


\section{Patients and their families}

$\mathrm{RD}$ patients presented in the movies were predominantly male (60\%), Caucasian (80\%), or children (56\%) who lived in rather stable social environments and were cared for by their families at home (60\%) (Table 3). The mortality rate for all twenty five patients depicted in the movies was $44 \%$. Of those who died, $64 \%$ passed away at home. Additionally, while $91 \%$ of deaths were caused by the disease itself, one character chose physician assisted suicide. Although most of these cinematic patients accepted their disease and the vision of inevitable death $(84 \%)$, some also experienced such negative emotions as depression $(28 \%)$, denial $(12 \%)$ or anger $(4 \%)$. The most commonly depicted medical obstacles were the lack of available treatment $(84 \%)$, high cost of drugs and care $(40 \%)$ and lack of scientific knowledge (24\%). $72 \%$ of patients' families showed those suffering the RD their love and support, although some denied the disease (16\%), blamed themselves for passing it on to their children $(12 \%)$ or were indifferent (24\%).

\section{Images of physicians and scientists}

The prototypical physician portrayed in movies was also Caucasian (75\%), middle aged (46\%) and male $(83 \%)$ (Table 4). While $75 \%$ of the cinematic scientists were leaders or chief physicians working in a hospital (92\%), $25 \%$ were assistants. Significantly, the majority of the latter were females. Additionally, most of the physicians engaged in the caring process were framed as benevolent, altruistic, empathic and committed doctors, caregivers, advisors and counsellors, who struggled to help their vulnerable patients and assisted their families in their distress (75\%) as well as fought the bureaucracy that impedes patients' access to novel treatment options.

\section{Psychosocial issues related to RDs}

Interestingly, irrespective of the veracity of the description of RDs, the vast majority of films highlighted RDs related psychosocial issues (Table 5). Thus, all patients struggled with negative social consequences of their diseases, such as reduced life opportunities (60\%), stigmatisation (48\%), isolation/social exclusion (48\%) or discrimination (32\%). Simultaneously, while concerns regarding the negative impact of the disease on the patient's quality of life and life opportunities were the most common trope, many films focused on how RD patients and their families are stigmatized because of the genetic nature of the disease. Thus, some films emphasized that RD patients experience structural stigma within societal structures, i.e. healthcare settings, workplaces or educational institutions. Simultaneously, while some films showed that healthcare providers' lack
Table 3 Patient characteristics $\left(\mathrm{N}=25^{*}\right)$

Sex

Male

Female

Age

Child

Adolescent

Adult

Ethnicity

Caucasian

Afro-Americans

Hindu

Type of care

Homecare

Hospital care

Home and hospital care

Prognosis

Survives

Dies

At home

In the hospital

$15 \quad 60$

$10 \quad 40$

ype of death

Natural death

Physician assisted suicide

Patient's reactions

Denial

Anger

Depression

Acceptance

Patient's problems and needs

Lack of access to correct diagnosis $\quad 2 \quad 8$

Lack of information

Lack of scientific knowledge

Lack of appropriate quality healthcare

Lack of treatment

High cost of drugs and care

Inequities in availability of treatment and care

Disturbance in family dynamics

Family reaction

Care/support

Feeling of blame

Disinterest/indifference

Lack of understanding

Denial

$14 \quad 56$

$7 \quad 28$

$4 \quad 16$

$20 \quad 80$

$3 \quad 12$

28

15

60

$4 \quad 16$

$6 \quad 24$

14

11

7

4

10

91

12

28

84

Some movies covered more than one patient

knowledge and the skills required to manage RDs (i.e. The Elephant Man, Lorenzo's Oil), others stressed how employers, co-workers or schools refuse to meet patient's needs (i.e. Mask, Children of the Dark, Wonder). Other 
Table 4 Images of physicians and scientists $\left(N=24^{*}\right)$

\begin{tabular}{|c|c|c|}
\hline & $\mathbf{N}$ & $(\%)$ \\
\hline \multicolumn{3}{|l|}{ Sex } \\
\hline Male & 20 & 83 \\
\hline Female & 4 & 17 \\
\hline \multicolumn{3}{|l|}{ Age } \\
\hline Young & 3 & 12 \\
\hline Middle age & 11 & 46 \\
\hline Older & 10 & 42 \\
\hline \multicolumn{3}{|l|}{ Ethnicity } \\
\hline Caucasian & 18 & 75 \\
\hline Asian & 2 & 8.3 \\
\hline Hindu & 4 & 16.7 \\
\hline \multicolumn{3}{|l|}{ Position } \\
\hline Leader/chief physician/scientist & 18 & 75 \\
\hline Assistant & 6 & 25 \\
\hline \multicolumn{3}{|l|}{ Type of researcher } \\
\hline Physician & 22 & 91.7 \\
\hline Individual researcher & 2 & 8.3 \\
\hline \multicolumn{3}{|l|}{ Place of work } \\
\hline Hospital/university clinic & 22 & 92 \\
\hline Private corporation & 1 & 4 \\
\hline University & 1 & 4 \\
\hline \multicolumn{3}{|l|}{ Attitude toward patient } \\
\hline Care/support & 18 & 75 \\
\hline Disinterest or insensitive behavior & 6 & 25 \\
\hline \multicolumn{3}{|l|}{ Physical appearance } \\
\hline Attractive & 11 & 45.8 \\
\hline Not attractive & 13 & 54.2 \\
\hline
\end{tabular}

*Some movies covered more than one physician

films focused on interpersonal stigma which occurs in patients' interactions with other individuals, including peers or neighbours. Thus, by showing lack of understanding from others, the movies suggested that RD patients suffer not only from the lack of diagnosis or treatment but also social support (i.e. Simon Birch, Mask, The Mighty). Finally, some films highlighted how RD patients suffer from a felt stigma and how they become somehow accustomed to being subjected to discrimination from others. Thus, The Boy in the Plastic Bubble, Mask, The Mighty, Children of the Dark, Wonder or Ondine show how RD patients, especially those with visible symptoms, feel shame about how they look or act because of their RD. All in all, most movies under the study showed how discrimination resulting from genetic condition reduces one's life opportunities, contributes to social inequity and negatively affects those with the stigmatized trait.
Table 5 Psychosocial issues related to RDs

\begin{tabular}{lll}
\hline & N & (\%) \\
\hline Stigmatisation & 12 & 48 \\
Isolation/social exclusion & 12 & 48 \\
Discrimination & 8 & 32 \\
Reduced life opportunities & 15 & 60
\end{tabular}

*Some movies covered more than one ELSI

\section{Discussion}

Although cinematic depictions of more common diseases have been the object of previous studies [34-37], to the best of my knowledge, this is the first descriptive analysis of the images of rare genetic disease in popular movies. Even though, compared to the total number of movies or those dealing with more common diseases, only a small number of films focus on rare genetic diseases, ${ }^{1}$ it must be acknowledged that over time this number is slowly increasing. Simultaneously, the vast majority of analysed movies were either produced in the United States or in cooperation between the US and European or Asian countries. However, this should not surprise, as the American film industry has a dominating power on the global movie market and its impact on popular culture and the global audiences is distinctive [38, 39].

At the same time, it should be stressed that because the majority of movies do not explain the specificity of RDs and often lack a more detailed scientific information on the RDs discussed in the movies, their cinematic image is rather superficial and vague. Cosnequently, the educational role of movies on the clinical dimension of RDs is limited. However, this should not surprise, as the main aim of popular culture is to entertain the audience rather than to educate. Because film is also a commercial product which needs to find an audience in order to make a profit, most popular movies introduce RDs only by highlighting their symptoms without adding a more detailed description. Conseqeuntly, they often rest on simplifications and reduce the information about the genetic aspects of RDs to a minimum in favour of making the picture more attractive and dramatic. Moreover, rarely do they explain the genetic basis of the disease discussed in the movie, and the majority do not contain any scientific information on RDs. Finally, some RDs are presented inaccurately and/or incorrectly. Especially the older

\footnotetext{
${ }^{1}$ Filmweb, which is the largest Polish movie database, covers more than 667,000 movies [personal communication with the Marketing and Sales Manager], and IMDB provides information on more than 730,000 movies (both cinema and TV movies) (https://www.imdb.com/pressroom/stats/). Thus, in both cases the number of movies depicting RDs is very low.
} 
movies, such as The Boy in the Plastic Bubble, Mask or Jack provide the audience only with the most basic information about the RD discussed in the movie, such as its name, that it is rare, and of genetic origin. On the other hand, while the cinematic description of cystic fibrosis in Jack and Jill vs. the World or And I'll Be Dead Tomorrow Noon or the Treacher Collins syndrome in Wonder is reduced to a couple of sentences expressed in scientific jargon, other movies, i.e. The Elephant Man, Crystal Heart or Simon Birch give no such information whatsoever (sometimes they even do not mention the name of the disease). What is also problematic is that many movies use RDs solely as a Hollywood teen love plot device. Thus, as they focus more on patients' desire for the mundane pleasures in life [27] they romanticize the terminal character of the RD and somehow trivialize it (The Boy in the Plastic Bubble, Crystal Heart, Jack and Jill vs. the World, Midnight Sun or Five Feet Apart). Finally, while some movie explore caregivers hopes and struggle to find a test or drug, they often falsely paint a picture of a miracle cure (Lorenzo's Oil).

However, this is not surprising because numerous studies indicate that cinematic depictions of common diseases too are often stereotypical, inaccurate and characterized by misinformation about symptoms, causes, and treatment. For example, people suffering from schizophrenia are frequently portrayed as unpredictable, violent, dangerous or committing homicide. Moreover, while the filmmakers tend to focus on hallucinations, traumatic events and violence, schizophrenic patients' socioeconomic status is also unrealistic [36, 40-42]. The cinematic image of autism spectrum disorder is also very far from being an accurate, representative or useful onethe reason for this being that films often concentrate on the extreme features of autism and reinforce the negative stereotypes of persons with ASD either as 'freaks' or 'geniuses' who speak in a monotone or rhythmic manner and have all the expected tics. Simultaneously, high functioning forms of autism are given prominence [43, 44]. While there is a progression in the understanding of epilepsy in many movies, it continues to be associated with the supernatural. Thus, although its older associations with insanity, uncontrolled violence or victimization tend to normalize, cinematic depictions of epilepsy still refer to demonic or divine possession, genius, lunacy, delinquency and "otherness" [45, 46]. Finally, films related to cancer focus on uncommon cancers such as leukemia and brain tumors, while such common types of cancer as breast cancer are barely represented. Consequently, films portray cancer patient's chances of survival inaccurately and in spite of the progress of cancer treatments they reinforce the stereotype of cancer as an incurable and lethal disease. Thus, it is suggested that popular images of cancer can instill carcinophobia, especially in that cinematic cancer often does not match the epidemiological data as filmmakers prefer younger patients and those from the higher social classes [47-49].

Nevertheless, some movies dealing with RDs contain "kernels of scientific truth" [27, 50]. In particular, Lorenzo's Oil, The Mighty, Extraordinary Measures and Five Feet Apart, provide the audience with detailed scientific information about the diagnosis of the RD, its aetiology, signs and symptoms, the availability of genetic testing and management, including therapy and medications or recent breakthroughs in understanding the disease. Consequently, the painful realities of adrenoleukodystrophy, Morquio syndrome, Pompe disease and cystic fibrosis depicted in these movies are particulary reliable and may increase public knowledge on these diseases.

This study also confirms previous findings regarding the cultural representations of scientists which show that although especially in earlier movies there was a tendency of the vilification of scientists and the good scientists were in the minority, from the 1990s and 2000s onwards the cinema has seen the ascendance of heroic scientists, who are pictured as idealist and hardworking professionals. Thus, while Andrew Tudor's [51], Roslynn Haynes [52, 53] and Sevan Terzian and Andrew Grunzke [54] showed that cinematic scientists are mainly framed either as foolish scientist-inventors or dangerous and deluded madmen, this research confirms observations from other research that suggest that in the twenty first century images of medical scientists are mainly positive. Thus, although still scientists are perceived in highly stereotyped, often unfavorable, ways, increasingly, they are framed as heroes [55-57]. Indeed, this research shows that in movies dealing with RDs physicians/scientists are mainly portrayed either as brilliant researchers who struggle to find a cure or as altruistic and empathic physicians and counsellors caring for their patients. Moreover, while the cinematic physician frequently fights the bureaucracy that impedes patients' access to available drugs or novel treatment options, he or she is not an alienated or dull individual, but a dedicated and tireless hero struggling to help vulnerable patients. For example, while in Extraordinary Measures, dr. Stonehill is a hardworking and rational researcher whose revolutionary medical theories and innovative research help to develop an enzyme treatment for Pompe disease, dr. Fleming in Midnight Sun is pictured as a caring physician, who cares for a girl suffering from a life-threatening sensitivity to sunlight caused by a rare genetic disorder.

At the same time, even though the cinematic portrayals of RDs often do not reflect the current scientific knowledge, movies do take up some important topics in the field of RDs. Indeed, while biomedicine often focusses on 
the clinical aspects of RDs, movies highlight their ethical, psychosocial, legal or economic dimension, which are often overlooked in the scientific discourse. For example, while picturing experimental therapy for cystic fibrosis Five Feet Apart depicts patients' experience with the disease, including coughing up blood, the inability to catch one's breath, emotional distress related to anticipated death, patient's dependence on the health system and the individual's everyday struggle with hospital life. Similarly, both Lorenzo's Oil and Extraordinary Measures show how deficits in scientific knowledge on RDs results in a confusing, chaotic, expensive and long-lasting diagnostic and therapeutic odyssey $[58,59]$. They also illustrate how RD parents often become lay/self-experts on their child's disease and the key players in the production of scientific knowledge. Moreover, although in both these movies the promise of a cure emerges, they also stress that RDs are too small to be easily funded and that finding a treatment is a time and money consuming enterprise. In Children of the Dark dr. Burnham while referring to the problem of orphan drugs explains to the parents of two girls suffering from xeroderma pigmentosum (XP) that it is not AIDS or cancer and therefore does not attract a lot of attention and that finding the cure for the RD may be 'a billion dollars and generation away'. Thus, while movies often cover parents' high hopes in research advances and their attempts to seek tests and drug trials, popular culture may help the public to understand how hard it is to handle the fiscal issues of RD drug development, how RD patients and their families struggle to get orphan drugs developed or how the bureaucracy impedes patients' access to available drugs or novel treatment options. Simultaneously, movies like Lorenzo's Oil or Extraordinary Measures stress the role of patient advocacy groups in $\mathrm{RD}$ research [60-62].

However, it is psychosocial issues related to RDs that are the most common tropes portrayed in the cinema. Indeed, all the analysed movies bring public attention to social stigmatization, isolation or discrimination resulting from patients' rare genetic condition [63, 64]. Thus, while all the main characters in The Elephant Man, Sixth Happiness, The Mighty, Simon Birch, Wonder or More Beautiful for Having Been Broken experience prejudices, social exclusion and reduced life opportunities, in the movie Mask "Rocky", who has craniodiaphyseal dysplasia, is also denied access to public school, and Jim's daughters with XP in Children of the Dark refuse to organize their first sleepover with friends because 'no one likes them. Additionally, many movies emphasize that as a result of RDs the entire family faces stigmatisation, marginalization and discrimination from the neighbours, peers, work colleagues or local community.
Most movies also highlight how RDs affect patients' entire life, influences one's concept of self and become a source of self-stigma $[65,66]$. For example, in The Boy in the Plastic Bubble, Tod, who suffers from severe combined immunodeficiency, becomes depressed after spending his entire life in incubator-like conditions, not being able to see the outside world and meet other people, and one day shouts loudly: "I'm so sick of it. I'm just feeling like a hospital case, like a weird kid who can't even breath normally because I'll get sick and die". Similarly, the title character Alex, a girl with cystic fibrosis, confesses to her father: "This disease is getting much bigger than me... I have to do what it wants me to do... And maybe if I try to be its friend it would be so angry with me" (Alex: The Life of a Child). The Polish movie Ondine depicting the story of a young male suffering from congenital central hypoventilation syndrome who hides his disease from the girl he loves and who fears to reveal his condition to the outside world illustrates how disease invades every part of Cezary's psychological self.

Another important theme depicted in movies includes the parents' feelings of shock after receiving test results and their experience of self-blame $[67,68]$. For example, both Michaela Odone in Lorenzo's Oil and Jim in Children of the Dark expressed recurring feelings of guilt and a strong sense of responsibility for what had occurred to their children, and couldn't stop blaming themselves for passing on "bad genes" to them. Finally, movies often stress how RDs affect family dynamics and relationships and creates tensions between spouses or between parents and their healthy children (The Mighty, Paa, Wonder, Children of the Dark).

\section{Conclusions}

Although popular movies have a great educational potential $[24,27,28]$, their utilization must be done under the premise that film is not science and that they are neither books nor scientific publications. Consequently, it should not surprise that rarely do the movies describe the clinical aspects of RDs as they mostly focus on patients' problems of daily living. Moreover, the scientific elements that do appear on screen are often presented for the sake of a script rather than medical education. However, while the cinema serves as a unique 'filter' by which individuals perceive and experience RDs, it is also a tool that helps the moviemakers to shape the collective imagination. This is important because while interpreting the reality of RDs the public uses its own language that does not refer to numbers, scales or scientific diagrams and figures.

Thus, it should be also noted that the cinematic images of RDs are not isolated artefacts but unique products of a complex cultural activity: while they reflect, to some 
degree, the social imagination on such diseases, they also influence the public's perception of RDs. Indeed, popular culture constitutes a unique symbolic resource and a "guide" which helps the audience to understand RDs. Even though the impact of popular culture on society is not decisive, it provides the public with images, examples and arguments for discussion on the clinical, psychosocial, ethical and economic implications of RDs. Cosnequently, as movies do co-create the interpretative context, they can significantly shape people's cultural values and social attitudes towards such diseases and may affect changes in existing RD legislations.

To conclude, because popular culture is currently one of the most important mediums and resources from which the public derives its knowledge, it is hard to overestimate its influence on the public understanding and acceptance of RDs-the reason for this being that popular movies reach a much wider segment of society and a single cinematic picture may have a bigger impact on social attitudes towards RDs than formal education. This is especially so in that for individuals who do not have contact with or access to science, movies are often the only source of information on RDs. Consequently, while the need for stronger educational initiatives for both medical students and healthcare professionals is required, popular culture, including movies, can also serve as an educational tool in this field.

\section{Limitations}

This study has some limitations. First, because the entire number of films picturing rare genetic diseases cannot be adequately determined, the selection of movies included into the analysis neither is nor could be representative. Second, only twenty popular movies on RDs were included into the analysis. Consequently, it would be desirable to extend the analysis and compare the content of popular films with different video formats that were not included, i.e. documentaries, short movies or even animations. Third, because the vast majority of the analysed movies were produced in the United States, the study sample is somehow biased as it under-represents European, Hispanic and Asian cinema. Fourth, as the entire analysis was performed by one author alone, there was a higher risk of subjectivity that might have influenced both the choice of the movies and the interpretation of the data. Finally, while it seems reasonable to argue that by using movies, popular culture puts the abstract and dire clinical information into the context of people's lives and thus advocates for RDs and increases public awareness of such diseases, it is unclear if and how far the audience responds to and is influenced by movies. However, despite these limitations, some advantages of this study should also be acknowledged. Most importantly, as there is a scarcity of previous work on the topic, this research fills a gap in the literature regarding the cinematic representations of rare genetic diseases. Moreover, by providing new insights, it emphasises the role of popular movies in enhancing the public's understanding of RDs.

\section{Abbreviation \\ RD: Rare disease.}

\section{Funding}

This research did not receive any specific grant from funding agencies in the public, commercial, or not-for-profit sectors.

\section{Availability of data and materials}

The datasets analyzed during the study are available from the corresponding author on reasonable request.

\section{Declarations}

Ethics approval and consent to participate

The study was exempt from review by the Ethics Committee based on the basis that this type of study is non-human subject research, and waived the need for informed consent.

\section{Consent for publication}

Not applicable.

\section{Competing interests}

The author declares no conflict of interest.

Received: 7 December 2021 Accepted: 20 February 2022

Published online: 05 March 2022

\section{References}

1. What is a rare disease? www.euror dis.org. Available online: https://www. eurordis.org/about-rare-diseases. Accessed 29 Oct 2021.

2. Miller KL, Fermaglich LJ, Maynard J. Using four decades of FDA orphan drug designations to describe trends in rare disease drug development: substantial growth seen in development of drugs for rare oncologic, neurologic, and pediatric-onset diseases. Orphanet J Rare Dis 2021;16(265). https://doi.org/10.1186/s13023-021-01901-6.

3. Giannuzzi V, Conte R, Landi A, et al. Orphan medicinal products in Europe and United States to cover needs of patients with rare diseases: an increased common effort is to be foreseen. Orphanet J Rare Dis. 2017;12(1):64. https://doi.org/10.1186/s13023-017-0617-1.

4. Li X, Lu Z, Zhang J, et al. The urgent need to empower rare disease organizations in China: an interview-based study. Orphanet J Rare Dis. 2020;15:282. https://doi.org/10.1186/s13023-020-01568-5.

5. Boffin N, Swinnen E, Wens J, et al. General practice care for patients with rare diseases in Belgium. A cross sectional survey. Int J Environ Res Public Health. 2018;15(6):1180. https://doi.org/10.3390/ijerph15061180.

6. Cismondi IA, Kohan R, Adams H, et al. Guidelines for incorporating scientific knowledge and practice on rare diseases into higher education: neuronal ceroid lipofuscinoses as a model disorder. Biochim Biophys Acta. 2015;1852:2316-23. https://doi.org/10.1016/j.bbadis.2015.06.018.

7. Vandeborne L, van Overbeeke E, Dooms M, De Beleyr B, Huys I. Information needs of physicians regarding the diagnosis of rare diseases: a questionnaire-based study in Belgium. Orphanet J Rare Dis. 2019;14:99. https://doi.org/10.1186/s13023-019-1075-8.

8. Li X, Zhang X, Zhang S, et al. Rare disease awareness and perspectives of physicians in China: a questionnaire-based study. Orphanet J Rare Dis 2021;16:171. https://doi.org/10.1186/s13023-021-01788-3. 
9. Walkowiak D, Domaradzki J. Needs assessment study of rare diseases education for nurses and nursing students in Poland. Orphanet J Rare Dis. 2020;15:167. https://doi.org/10.1186/s13023-020-01432-6.

10. Domaradzki J, Walkowiak D. Knowledge and attitudes of future healthcare professionals towards rare diseases. Front Genet. 2021;12: 639610. https://doi.org/10.3389/fgene.2021.639610.

11. Walkowiak D, Domaradzki J. Are rare diseases overlooked by medical education? Awareness of rare diseases among physicians in Poland: an explanatory study. Orphanet J Rare Dis. 2021;16:400. https://doi.org/10. 1186/s13023-021-02023-9.

12. Wise J. Rare diseases are overlooked by doctors, policy makers, and guidelines, says think tank. BMJ. 2012;345: e6604. https://doi.org/10.1136/ bmj.e6604.

13. Saviano M, Barile S, Caputo F, Lettieri M, Zanda S. From rare to neglected diseases: a sustainable and inclusive healthcare perspective for reframing the orphan drugs issue. Sustainability. 2019;11(5):1289. https://doi.org/10. 3390/su11051289.

14. Budych $K$, Helms TM, Schultz C. How do patients with rare diseases experience the medical encounter? Exploring role behavior and its impact on patient-physician interaction. Health Policy. 2012;105:154-64. https://doi. org/10.1016/j.healthpol.2012.02.018.

15. Anderson M, Elliott EJ, Zurynski YA. Australian families living with rare disease: experiences of diagnosis, health services use and needs for psychosocial support. Orphanet J Rare Dis. 2013;8:22. https://doi.org/10. 1186/1750-1172-8-22

16. Domaradzki J. Family caregivers' experiences with healthcare services-a case of Huntington disease. Psychiatr Pol. 2016;50:375-91. https://doi. org/10.12740/PP/59103.

17. Harari S. Why we should care about ultra-rare disease. Eur Respir Rev. 2016;25:101-3. https://doi.org/10.1183/16000617.0017-2016.

18. Schieppati A, Henter J-I, Daina E, Aperia A. Why rare diseases are an important medical and social issue. Lancet. 2008;371(9629):2039-41. https://doi.org/10.1016/S0140-6736(08)60872-7.

19. Bokayeva K, Miraleyeva A, Walkowiak D. Rare diseases-a challenge for the medical world. J Med Sci. 2021;90:e503. https://doi.org/10.20883/ medical.e503.

20. Valdez R, Grosse SD, Khoury MJ. The need for a next-generation public health response to rare diseases. Genet Med. 2016;19(5):489-90. https:// doi.org/10.1038/gim.2016.166.

21. Moliner AM, Waligora J. The European Union Policy in the field of rare diseases. Adv Exp Med Biol. 2017;1031:561-87. https://doi.org/10.1007/ 978-3-319-67144-4_30.

22. Khosla N, Valdez R. A compilation of national plans, policies and government actions for rare diseases in 23 countries. Intractable Rare Dis Res. 2018;7(4):213-22. https://doi.org/10.5582/irdr.2018.01085.

23. Montserrat A, Taruscio D. Policies and actions to tackle rare diseases at European level. Ann Ist Super Sanita. 2019;55(3):296-304. https://doi.org/ 10.4415/ANN_19_03_17.

24. Klemenc-Ketis Z, Kersnik J. Using movies to teach professionalism to medical students. BMC Med Educ. 2011;11:60. https://doi.org/10.1186/ 1472-6920-11-60.

25. Drukarczyk L, Klein C, Ostgathe C, Stiel S. Life threatening illness in popular movies-a first descriptive analysis. Springerplus. 2014;3:411. https:// doi.org/10.1186/2193-1801-3-411.

26. García Sánchez JE, García SE. Rare diseases in the cinema. J Med Mov. 2005;1:93-4.

27. Costa LV, Veloso Al. Portraying rare and misdiagnosed diseases in movies: A content analysis, 1980-2018. In: Association IRM, editor. Research anthology on improving health literacy through patient communication and mass media. Hershey: PA; 2022. p. 108-26.

28. The Rare Disease Film Festival, 2022. https://www.rarediseasefilmfestival. com. Accessed 29 October 2021

29. Legendre CM, Charpentier-Côté C, Drouin R, Bouffard C. Neurofibromatosis type 1 and the "elephant man's" disease: the confusion persists: an ethnographic study. PLOS ONE. 2011;6(2): e16409. https://doi.org/10. 1371/journal.pone.0016409.

30. von der Lippe C, Diesen PS, Feragen KB. Living with a rare disorder: a systematic review of the qualitative literature. Mol Genet Genomic Med. 2017;5(6):758-73.

31. Cohen JS, Biesecker BB. Quality of life in rare genetic conditions: a systematic review of the literature. Am J Med Genet A. 2010;152A(5):1136-56.
32. Uhlenbusch N, Löwe B, Depping MK. Perceived burden in dealing with different rare diseases: a qualitative focus group study. BMJ Open. 2019;29(12):e033353. https://doi.org/10.1136/bmjopen-2019-033353.

33. Elliott E, Zurynski Y. Rare diseases are a'common' problem for clinicians. Aust Fam Phys. 2015;44(9):630-3.

34. Lederer SE. Dark victory: cancer and popular Hollywood film. B Hist Med. 2007;81(1):94-115. https://doi.org/10.1353/bhm.2007.0005.

35. Karenberg A. Multiple sclerosis on-screen: from disaster to coping. Mult Scler J. 2008;14(4):530-40. https://doi.org/10.1177/1352458507084587.

36. Owen PR. Portrayals of schizophrenia by entertainment media: a content analysis of contemporary movies. Psychiatr Serv. 2012;63(7):655-9. https://doi.org/10.1176/appi.ps.201100371.

37. Nordahl-Hansen A, Tøndevold M, Fletcher-Watson S. Mental health on screen: a DSM-5 dissection of portrayals of autism spectrum disorders in film and TV. Psych Res. 2018;262:351-3. https://doi.org/10.1016/j. psychres.2017.08.050.

38. Segrave K. 1997. American films abroad: Hollywood's domination of the world's movie screens from the 1890s to the present. North Carolina: McFarland.

39. De Zoysa R, Newman O. Globalization, soft power and the challenge of Hollywood. Contemp Polit. 2002;8(3):185-202. https://doi.org/10.1080/ 1356977022000025678.

40. Hyler SE, Gabbard GO, Schneider I. Homicidal maniacs and narcissistic parasites: stigmatization of mentally ill persons in the movies. Hosp Community Psychiatry. 1991;42(10):1044-8. https://doi.org/10.1176/ps. 42.10.1044.

41. Pirkis J, Blood RW, Francis C, McCallum K. On-screen portrayals of mental illness: extent, nature, and impacts. J Health Commun. 2006;11(5):523-41. https://doi.org/10.1080/10810730600755889.

42. Wahl O. Media madness: public images of mental distress. New Brunswick: Rutgers University Press; 1995.

43. Anjay MA, Palanivel V, Palanivel J. Beyond stereotypes: a historical analysis of how autism spectrum disorder is depicted in movies. Arch Dis Child. 2011;96:A44. https://doi.org/10.1136/adc.2011.212563.97.

44. Conn R, Bhugra D. The portrayal of autism in Hollywood films. Int J Cult Ment Health. 2012;5(1):54-62. https://doi.org/10.1080/17542863.2011. 553369.

45. Baxendale S. Epilepsy at the movies: possession to presidential assassination. Lancet Neurol. 2003;2(12):764-70. https://doi.org/10.1016/ s1474-4422(03)00589-1.

46. Baxendale S. Epilepsy on the silver screen in the 21st century. Epilepsy Behav. 2016;57(Pt B):270-4. https://doi.org/10.1016/j.yebeh.2015.12. 044.

47. De Fiore L, Costantini A, Di Maio M, Gori S, Lorusso D, Rosti G, Pinto C. Il cancro sul grande schermo. Quanto, come e quando il cinema si occupa delle malattie oncologiche. Recenti Prog Med. 2014;105(5):198209. https://doi.org/10.1701/1493.16455.

48. Icart-Isern MT, Rozas-García MR, Sanfeliu-Cortes V, Viñas-Llebot H, Fernández-Ortega MP, Icart MC. El cáncer en el cine. Un recurso para los profesionales de la salud. Educ Méd. 2009; 12(4): 234-246. https:// doi.org/10.4321/S1575-18132009000500006.

49. Burki TK. Life improving on art: paediatric cancer on film. Lancet Oncol. 2014;15(10): p1064. https://doi.org/10.1016/S1470-2045(14)70429-2.

50. Rose C. Biology in the movies: using the double-edged sword of popular culture to enhance public understanding of science. Evol Biol. 2007;34(1-2):49-54. https://doi.org/10.1007/s11692-007-9001-8.

51. Tudor A. Monsters and mad scientists. Oxford: Basil Blackwell; 1989.

52. Haynes RD. From faust to from faust to strangelove. Baltimore: The John Hopkins University Press; 1994.

53. Haynes RD. The alchemist in fiction: the master narrative. HYLE Int J Phi Chem. 2006;12(1):5-29. https://doi.org/10.1142/9789812775856_0002.

54. Terzian SG, Grunzke AL. "Scrambled eggheads: ambivalent representations of scientists in six hollywood film comedies from 1961 to 1965. Public Underst Sci. 2007;16(4):407-19. https://doi.org/10.1177/09636 62506067908.

55. Väliverronen E. Expert, healer, reassurer, hero and prophet: Framing genetics and medical scientists in television news. New Genet Soc. 2006;25(3):233-47. https://doi.org/10.1080/14636770601032742.

56. Haynes RD. Whatever happened to the 'mad, bad'scientist? Overturning the stereotype. Public Underst Sci. 2016;25(1):31-44. https://doi. org/10.1177/0963662514535689. 
57. Haynes RD. From madman to crime fighter. The scientist in western culture. Baltimore, MD: Johns Hopkins University Press, 2017.

58. Black N, Martineau F, Manacorda T. Diagnostic odyssey for rare diseases: exploration of potential indicators. London: Policy Innovation Research Unit, LSHTM; 2015.

59. Carmichael N, Tsipis J, Windmueller G, Mandel L, Estrella E. "Is it going to hurt?" the impact of the diagnostic odyssey on children and their families. J Genet Couns. 2015;24:325-35. https://doi.org/10.1007/ s10897-014-9773-9.

60. Dunkle M, Pines W, Saltonstall PL. Advocacy groups and their role in rare diseases research. Adv Exp Med Biol. 2010;686:515-25. https://doi.org/10. 1007/978-90-481-9485-8_28.

61. Dunkle M. A 30-year retrospective: National Organization for Rare Disorders, the Orphan Drug Act, and the role of rare disease patient advocacy groups. Orphan Drugs Res Rev. 2014;4:19-27. https://doi.org/10.2147/ ODRR.S41070.

62. Wood J, Sames L, Moore A. Ekins S. Multifaceted roles of ultra-rare and rare disease patients/parents in drug discovery. Drug Discov Today 2013;18(21-22):1043-105. https://doi.org/10.1016/j.drudis.2013.08. 006.

63. Klitzman R. Views of discrimination among individuals confronting genetic disease. J Genet Couns. 2010;19(1):68-83. https://doi.org/10. 1007/s10897-009-9262-8.

64. Munro M, Cook AM, Bogart KR. An inductive qualitative content analysis of stigma experienced by people with rare diseases. Psychol Health. 2021;22:1-16. https://doi.org/10.1080/08870446.2021.

65. Klitzman R. Am I my genes? Questions of identity among individuals confronting genetic disease. Genet Med. 2009;1 1(12):880-9. https://doi. org/10.1097/GIM.0b013e3181bfd212.

66. Williams JK, Ayers L, Specht JK, Sparbel KJ, Klimek ML. Caregiving by teens for family members with Huntington disease. J Fam Nurs. 2009;15(3):27394. https://doi.org/10.1177/1074840709337126.

67. James CA, Hadley DW, Holtzman NA, Winkelstein JA. How does the mode of inheritance of a genetic condition influence families? A study of guilt, blame, stigma, and understanding of inheritance and reproductive risks in families with X-linked and autosomal recessive diseases. Genet Med. 2006;8(4):234-42. https://doi.org/10.1097/01.gim.0000215177.28010.6e.

68. Arribas-Ayllon M, Sarangi S, Clarke A. Managing self-responsibility through other-oriented blame: family accounts of genetic testing. Soc Sci Med. 2008;66(7):1521-32. https://doi.org/10.1016/j.socscimed.2007.12. 022.

\section{Publisher's Note}

Springer Nature remains neutral with regard to jurisdictional claims in published maps and institutional affiliations.

Ready to submit your research? Choose BMC and benefit from:

- fast, convenient online submission

- thorough peer review by experienced researchers in your field

- rapid publication on acceptance

- support for research data, including large and complex data types

- gold Open Access which fosters wider collaboration and increased citations

- maximum visibility for your research: over $100 \mathrm{M}$ website views per year

At BMC, research is always in progress.

Learn more biomedcentral.com/submissions 